\title{
Emerging Pollutant of Concern: Occurrence of Pharmaceutical Compounds in Asia with Particular Preference to Southeast Asia Countries
}

\author{
Nor Haslina Hashim ${ }^{1, a}$, Muhammad Hafiz Nasir ${ }^{2}$ and Muhammad Syamim Ramlee ${ }^{2}$ \\ ${ }^{1}$ Faculty of Engineering Technology, Universiti Tun Hussein Onn Malaysia, 86400 Parit Raja, Malaysia \\ ${ }^{2}$ Faculty of Civil and Environmental Engineering, Universiti Tun Hussein Onn Malaysia, 86400 Parit Raja, Johor, \\ Malaysia
}

\begin{abstract}
Southeast Asia countries were developing countries, with the rapid development for a better living condition leads to longer life expectancy, which increased total population. It may result in increased the demand of pharmaceutical in domestic use and or in hospital. Although most wastewater treatment plants (WWTPs) met the local authority's regulatory requirement, there are still many pharmaceutical compound incompletely removed and discharge to the water stream and enter the environment. Recently many studies and researches have published on the occurrence and source as well as the fate of pharmaceuticals all over the world including Asia. As part of Asia region, Southeast Asia countries (Malaysia, Philippines, Singapore, Thailand, Vietnam, Brunei, Cambodia, and Lao PDR) seem has lack of research knowledge and information regarding this emerging pollutant issues compared to developed Asia country as China, Korea and Hong Kong. In this paper, it will review recent studies occurrences (surface and wastewater) on most common pharmaceuticals with several recommendations to overcome and thus summarise the actual situation in Southeast Asia.
\end{abstract}

\section{Introduction}

Recently, the World Health Organization (WHO), authorities and researcher across Europe, North America, and elsewhere have emphasized the concern regarding potential aquatic ecosystems and human health impacts connected to contaminants of this emerging pollutant [1]. Pharmaceutical are part group of emerging, probably hazardous pollutants that have attract highly concern among researcher and scientist in recent years. These compounds among the emerging environment issue lately. Pharmaceutical compounds has detected in surface water, wastewater treatment plants (WWTPs) influent and effluent, and in the hospital effluent [2].

The Asian Development Bank (ADB), in a widely acclaimed paper published in 2001, accused Southeast Asia of having the world's dirtiest environment (land, sea and air). Urban corridors such as Kuala Lumpur's Klang Valley and Singapore Island seem to have the pollution situation more or less under control. Currently, there are few published reports of pharmaceutical compounds in this region. Alkylated musk recently has been measure of wastewater treatment in Guangdong, China [3]. In 2003, China was the world's largest producer of pharmaceutical products, with an annual production of

\footnotetext{
${ }^{a}$ Corresponding author : haslina@uthm.edu.my
} 
28,000 tonnes of penicillin $(60 \%$ of the world total). At present, little is known about the adverse effects of human and veterinary pharmaceuticals on aquatic organisms, although standard acute toxicity data have been reported for some pharmaceuticals [4].

\section{Occurrences}

The occurrence of pharmaceutical in surface water and wastewater is already published and well documented in European and North American countries [5-8]. A published research concerning the occurrence of pharmaceutical active compounds in aquatic environments in Southeast Asia countries reviewed by Richardson [9] and indicated has no environment data for the fate and effects have been reported in Southeast Asia before 2005. Other than that, developing countries generally has poor treatment to treat wastewater or less advanced than the developed countries because of the lower economic budget. Thus, effluent was released to surface stream water without specific treatment.

\subsection{Surface water}

The occurrence of pharmaceuticals in surface water has been summarised and shown in Table 1 (selected Southeast Asia countries) which is obtained from recent studies. In Asia, the antibiotic concentrations such as Oxytetracyclin, Trimethoprim and Sulfamethoxazole are high in both wastewater influent effluent and surface water [10]. In additional, researcher analyzed for 10 NSAIDs, 2 blood lipid regulators, and 2 antiepileptic drugs in the Pearl River system in China (Liuxi, Zhujiang, and Shijin Rivers) and four sewage effluents during the dry and wet seasons, results were reported and the environmental risks they posed were assessed [11].

Table 1. Detection of selected pharmaceutical compound in surface water of several Southeast Asia countries.

\begin{tabular}{|c|c|c|c|c|}
\hline Country & Location & Compound & Conc. (ng/L) & Ref \\
\hline \multirow{3}{*}{ Taiwan } & \multirow{3}{*}{ Taiwanese River } & Ketoprofen & $110-620$ & \multirow{3}{*}[12]{} \\
\hline & & Ibuprofen & $<12-30$ & \\
\hline & & Diclofenac & $24-62$ & \\
\hline \multirow{4}{*}{ Vietnam } & \multirow{4}{*}{ Hanoi } & Ketoprofen & $<40-330$ & \multirow{4}{*}{13} \\
\hline & & Ibuprofen & $100-1100$ & \\
\hline & & Diclofenac & $<140-310$ & \\
\hline & & Naproxen & $80-380$ & \\
\hline \multirow{8}{*}{ Singapore } & \multirow{4}{*}{ Marina Bay } & Naproxen & $>12-24$ & \multirow{8}{*}[14]{} \\
\hline & & Ketoprofen & $>3-23$ & \\
\hline & & Diclofenac & $>4-26$ & \\
\hline & & Ibuprofen & $>37-60$ & \\
\hline & \multirow{4}{*}{ Rochor Canal } & Naproxen & 20 & \\
\hline & & Ketoprofen & 25 & \\
\hline & & Diclofenac & Below Detection & \\
\hline & & Ibuprofen & 139 & \\
\hline \multirow[t]{2}{*}{ Malaysia } & \multirow{2}{*}{ Langat and Muar Rivers } & Caffeine & $138-760$ & \multirow{2}{*}[15]{} \\
\hline & & Diclofenac & Non Detect-54 & \\
\hline
\end{tabular}

Other in China, river water and tap water screened for the presence of $\beta$-lactam antibiotics. River water samples were collected from upstream to downstream, which a drainage river that connects with a drainage ditch of the pharmaceutical factories located in this area, and receives the effluent from two WWTPs. The $\beta$-lactam antibiotics were found within the range of $0-9.56 \mu \mathrm{g} / \mathrm{L}$ in river water at the downstream of antibiotics manufacturers, and none were detected in the tap water [16]. Further in Southeast Asia country, researcher identified a method to determine the risk of pharmaceutical compounds applied it to 10 of the human-use pharmaceuticals detected in Taiwan's Sindian River [17]. Additionally, they showed that in river water samples, NSAIDs, steroids, propranolol, and 
gemfibrozil were found at $\mathrm{ng} / \mathrm{L}$ to $\mathrm{mg} / \mathrm{L}$ levels with night-time concentrations of these compounds, except estrogens, doubled or even greater, compared to day-time levels. Table 1 provide an overview of the various pharmaceuticals in surface, with the concentrations recoded in Asia countries. Meanwhile, scientist developed and applied a method for quantification of 10 pharmaceuticals in surface water samples from the major rivers in South Korea. Results showed that overall, surface water contamination near livestock WWTPs was higher than near domestic WWTPs [18]. Experimenter collected samples from upstream/downstream and effluent dominated creeks along the Han River, Seoul (South Korea) and examined them for selected emerging pollutants. Most target compounds were detected in both the Han River samples $(63 \%)$ and in the effluent dominated creek samples (79\%). Both river and creek samples were frequently detected atenolol, musk ketone, naproxen, carbamazepine, caffeine, and benzophenone, although the mean concentrations in effluent dominated creek samples $(102-3745 \mathrm{ng} / \mathrm{L})$ were significantly higher than those in river samples (56$1013 \mathrm{ng} / \mathrm{L})$. However, steroid hormones 17 $\beta$-estradiol, 17 $\alpha$ ethynylestradiol, progesterone, and testosterone, were not detected $(<1 \mathrm{ng} / \mathrm{L})$ in both samples [19].

\subsection{Wastewater}

Many research reported that those WWTPs, which meet the regulatory requirement for waste water treatment are only moderately effective in removing the pharmaceuticals, expect the plants install with a tertiary treatment [20]. Occurrence and fate of selected pharmaceutical compound were investigated in three WWTPs in Beijing, China. All of the pharmaceutical compounds were detected in the influents of all three WWTPs with bisphenol-A being the most abundant compound detected [21]. In another study, four WWTPs in Beijing, China were investigated on occurrence and removal of 13 pharmaceuticals and 2 consumer products, including antibiotic, anti-lipidemic, anti-inflammatory, anti-hypertensive, insect repellent and antipsychotics [22].

Meanwhile in Malaysia, researcher developed a method for simultaneous determination and quantification of 23 pharmaceuticals and synthetic hormones from different therapeutic classes in water samples and applied the method to river water and WWTP effluents with results showing that among target compounds, chlorothiazide was found at the highest level, with concentrations reaching up to $865 \mathrm{ng} / \mathrm{L}$ in WWTP effluent, and $182 \mathrm{ng} / \mathrm{L}$ in river water [23]. In Korea, scientist studied the occurrence and fate of pharmaceuticals in WWTPs and rivers found that pharmaceuticals were present. The researched found biological processes in the WWTP showed the greatest efficacy for reducing the concentration of the pharmaceuticals. Overall, although conversional wastewater treatments only partially remove concentration pharmaceutical several compound, while some of the pharmaceuticals are resistant to degradation and persistent in the environment [24]. The result of WWTPs is still unsatisfactory.

Table 2. Detection of selected pharmaceutical compound in wastewater of several Asia countries.

\begin{tabular}{ccc}
\hline Country & Compound & Ref. \\
\hline \multirow{2}{*}{ Malaysia } & Chlorothiazide & {$[23]$} \\
\cline { 2 - 3 } & Chloramphenicol & {$[28]$} \\
\hline \multirow{2}{*}{ Pakistan } & Oxytetracyclin & {$[29]$} \\
\cline { 2 - 3 } & Trimethoprim & {$[29]$} \\
\hline China & bisphenol-A & {$[21]$} \\
\hline
\end{tabular}

Via search engine from Sciences Direct website, based on "Occurrence of pharmaceutical active compounds in Southeast Asia" and "Occurrence of pharmaceutical active compounds in Europe" in between 2010 until 2015 (recently- 1 July), a comparison are made to visualise the few amount of publication of journal and research about this emerging pollutant in Asia region. Only few studies are available regarding the occurrence of Pharmaceutical Active Compounds (PAC's) in all of environment matrices including industry wastewater, domestic wastewater, hospital wastewater, surface water, and sediments of Southeast Asia countries. Thus detailed and focused investigations 
specifically in Southeast Asia are required to determine the sources, pathway and fate of these PACs and their biological resistance in the entire environment.

\section{Conclusion}

The important action should be taken instantly by upgrading available system for treating wastewater in Southeast Asia countries because there are still high concentrations found in effluent WWTPs. According to research, the removal of pharmaceuticals is still incomplete except WWTPs includes tertiary treatment [25]. A study found that the removal efficiency is different with divergent filtration. Biological Activated Carbon (BAC) filtration is more effective to remove the pharmaceuticals compare to sand filtration [26]. Other than improving the treatment system process in WWTPs, it is important for government to set regulation globally. Each country has a government body that is responsible for the control of environmental pollution. The formulation of policy, enforcement and implementation of regulation vary from country to country depending on various factors. Some countries have stringent regulation and enforce it strongly; some have slow approach, where as some are still in primary stage of environmental protection. In some countries, the implementation part is very weak that it cannot enforce the existing regulation effectively due to inexperienced manpower and financial constraints. Some countries are still concentrating on rapid economic development through industrialization at the cost of environment damage. Meanwhile, government in each Southeast Asia countries need to create a module to educate their own citizen awareness this emerging pollutant issues.

It is well known that there has not been sufficient evaluation of pharmaceutical residue in environment from the Southeast Asian region. Evaluation and reporting inventories of production and usage of pharmaceutical compound products in all countries of Southeast Asia is essential needs. The volume of pharmaceutical industry and human population in these countries has increase significant of pharmaceutical contamination and its associated risk. The approach and framework of Southeast Asian Mussel Watch is appropriate plan to organise local scientists and researchers into common aim and focussed of contaminant measurement [27]. In response to this, suggested that government should establish more resources cooperate nationally with country between Asia region and globally with Europe and North America in order to know more about the effect and hence setting up with different pharmaceutical compounds. Therefore the well knows it toxicity; impact or monitoring data can achieve. Lastly each Southeast Asia countries should assemble regulation to control the use and disposal of this pharmaceutical to eliminate probable chance discharging the residue to the environment.

\section{References}

[1] World Health Organization, Pharmaceuticals in Drinking-Water, Water Sanitation Health, (2012).

[2] M.J. Gomez, M. Petrovic, A.R. Fernandez-Alba and D. Barcelo, Determination of pharmaceutical of various therapeutic classes by solid-phase extraction and liquid chromatography-tandem mass spectrometry analysis in hospital effluent wastewaters, J. Chromatogr. A111, 4(2), 224-233, (2006).

[3] X. Zeng, G. Sheng, Y. Xiong and J. Fu, Determination of polycyclic musks in sewage from Guangdong China using gas chromatography-electron impact-mass spectrometry, Chemosphere, 60(6), 817-823, (2005).

[4] D. Pascoe, W. Karntanut and C.T. Muller, Do pharmaceuticals affect freshwater invertebrates? A study with the cnidarian Hydra vulgaris, Chemosphere, 51, 521-528, (2003).

[5] D.W. Koplin, E.T. Furlong, M.T. Meyer, E.M. Thurman, S.D. Zaugg, L.B. Barber and H.T. Buxton, Pharmaceuticals, hormones, and other organic wastewater contaminant in U.S. stream, Environmental Science and Technology, 36, 1202-1211, (2002).

[6] K.V. Thomas and M.J Hilton, The occurrence of selected human pharmaceutical compounds in UK Estuaries, Marine Pollution Bulletin, 49, 436-444, (2004). 
[7] A. Nikolaou, S. Meric and D. Fatta, Occurrence patterns pharmaceuticals in water and wastewater environments, Analytical Bioanalytical Chemistry, 387, 1225-1234, (2007).

[8] S. Zhang, Q. Zhang, S. Darisaw, O. Ehie, and G. Wang, Simultaneous quantification of polycyclic aromatic hydrocarbons (PAHs), polychlorinated biphenyls (PCBs), and pharmaceuticals and personal care products (PPCPs) in Mississippi river water in New Orleans, Louisiana, USA Chemosphere, 66, 1057-1069, (2007).

[9] B.J. Richardson, P.K.S. Lam and M. Martin, Emerging chemical of concern: pharmaceutical and personal care products (PPCPs) in Asia, with particular reference to Southern China, Mar. Pollut. Bull., 50, 913-920, (2005).

[10]P.T. Hoa, S. Managaki, N. Nakada, H. Takada, A. Shimizu, D.H. Anh, P.H. Viet and S. Suzuki, Antibiotic contaminant and occurrence of antibiotic-resistant bacteria in aquatic environment in northern Vietnam, Sci. Total Environ., 409, 2894-2901, (2011).

[11]J.L. Zhao, G.G. Ying, Y.S. Liu, F. Chen, J.F. Yang, L. Wang, X.B. Yang, J.L. Stauber and M.S.J. Warne, Occurrence and a screening-level risk assessment of human pharmaceuticals in the Pearl River system, South China. Environ. Toxicol. Chem., 29(6), 1377-1384, (2010).

[12]C.C. Hsin, L.W. Pi and H.S. Wang, Using liquid chromatography ion trap mass spectrometry to determine pharmaceutical residues in Taiwanese rivers and wastewaters, Chemosphere, 72, 863$869,(2008)$.

[13]N.H. Tran, T. Urase and T.T. Ta, A preliminary study on the occurrence of pharmaceutically active compounds in hospital wastewater and surface water in Hanoi, Vietnam, CLEAN - Soil, Air, Water, 42(3), 267-275, (2014).

[14]J. Wu, J. Yue, R. Hu, Z. Yang and L. Zhang, Use of caffeine and human pharmaceutical compounds to identify sewage contamination, Int. J. of Medical, Health, Biomedical, Bioengineering and Pharmaceutical Engineering, 2(8), 289-293, (2008).

[15]F.A.Q. Fouad, M.P. Abdullaha, R. O. Mohamed, J. Latipa and Z. Zakaria, Multi-residue analytical methodology-based liquid chromatography-time-of-flight-mass spectrometry for the analysis of pharmaceutical residues in surface water and effluents from sewage treatment plants and hospitals, J. Chromatogr. A., 1345, 139-153, (2014)

[16]J. Yin, Z. Meng, M. Du, C. Liu, M. Song and H. Wang, Pseudo-template molecularly imprinted polymer for selective screening of trace Betalactam antibiotics in river and tap water, J. Chromatogr., A. 1217(33), 5420-5426, (2010).

[17]A.Y.C. Lin, C.F. Lin, Y.T. Tsai, H.H.H. Lin, J. Chen, X.H. Wang and T.H. Yu, Fate of selected pharmaceuticals and personal care products after secondary wastewater treatment processes in Taiwan, Water Sci. Technol., 62 (10), 2450-2458, (2010).

[18] S.H. Koo, C.H. Jo, S.K. Shin and S.W. Myung, Simultaneous determination and occurrences of pharmaceuticals solid-phase extraction and liquid chromatography-tandem mass spectrometry (LC-MS/MS) in environmental aqueous samples, Bull. Korean Chem. Soc., 31(5), 1192-1198, (2010).

[19]Y. Yoon, J. Ryu, J. Oh, B.G. Choi and S.A. Snyder, Occurrence of endocrine disrupting compounds, pharmaceuticals, and personal care products in the Han River (Seoul, South Korea), Sci., Total Environ., 408(3), 636-643, (2010).

[20]P. Gao, D. Mao, Y. Luo, L. Wang, B. Xu and L. Xu, Occurrence of sulphonamide and tetracycline-resistant bacteria and resistance genes in aquaculture environment, Water Res., 46, 2355-66, (2012).

[21]L. Zhou, C. Gao and W. Xu, Magnetic dendritic materials for highly efficient adsorption of dyes and drugs, ACS Appl. Mater. Interfaces, 2(5), 1483-1491, (2010).

[22]Q. Sui, J. Huang, S. Deng, G. Yu and Q. Fan, Occurrence and removal of pharmaceuticals, caffeine and DEET in wastewater treatment plants of Beijing, China, Water Res., 44(2), 417-426, (2010).

[23]N.A. Al-Odaini, M.P. Zakaria, M.I. Yaziz and S. Surif, Multi-residue analytical method for human pharmaceuticals and synthetic hormones in river water and sewage effluents by solidphase 


\section{MATEC Web of Conferences}

extraction and liquid chromatographytandem mass spectrometry, J. Chromatogr., A. 1217(44), 6791-6806, (2010).

[24] W.J. Sim, J.W. Lee and J.E. Oh, Occurrence and fate of pharmaceuticals in wastewater treatment plants and rivers in Korea, Environ. Pollut. (Oxford), 158(5), 1938-1947, (2010).

[25]A. Jelic, N. Gros, A. Ginebreda, R. Chespedes-Sancez, F. Ventura, M. Petrovic and D. Barcelo, Occurrence, partition, and removal of pharmaceuticals in sewage water and sludge during wastewater treatment, Water Res., 45, 1165-1176, (2011).

[26]J. Reungoat, B.I. Escher, M. Macova and J. Keller, Biofiltaration of wastewater treatment plant effluent: Effective removal of pharmaceutical and personal care products and reduction of toxicity, Water Res., 45, 2751-2762, (2011).

[27]L. Monirith, D. Ueno, S. Takahashi, H. Nakata, A. Sudaryanto, A. Subramanian, S. Karuppiah, A. Ismail, M. Muchtar, J. Zheng, Asia-Pacific mussel watch: monitoring contamination of persistent organochlorine compounds in coastal water of Asian countries, Mar. Pollut. Bull., 46, 281-300, (2003).

[28] S.A. Marni, N.T. Malintan, I. Faridah, A. M. Mustafa, Chloramphenicol in Malaysia waste water and its residues in animal husbandaries products, Health and the Environment Journal, 1(1), 4145, (2010).

[29] M. Ahmad, A. U. Khan, A. Wahid, Z. A. Butt, M. Farhan, F. Ahmad, Role of hospital effluents in the contribution of antibiotics and antibiotic resistant bacteria to the aquatic environment, Pak. J. Nutr., 11(12), 1177-1182, (2012). 